\title{
Age dependent efficacy of implantable cardioverter-defibrillator treatment: observations in 450 patients over an 11 year period
}

Hans-Joachim Trappe, Petra Pfitzner, Michael Achtelik, Hans-Gerd Fieguth

\begin{abstract}
Objective-To determine whether implantable cardioverter-defibrillator (ICD) treatment is beneficial in elderly patients with life threatening ventricular tachyarrhythmias.
\end{abstract}

Design-Since January 1984, ICDs were implanted in 450 patients to evaluate surgical risk, complications and mean survival in relation to patient age; 81 patients $(18 \%)$ were $\leqslant 50$ years at the time of ICD implant, 254 patients $(56 \%)$ were between 51 and 64 years, and the remaining 115 $(26 \%)$ were $\geqslant 65$ years. Epicardial lead systems were implanted in 209 patients $(46 \%)$, while transvenous lead systems were implanted in $241(54 \%)$.

Results-13 patients (3\%) died perioperatively, more often after epicardial (11 of 209 patients, $5 \%$ ) than after transvenous ICD implantation (one of 241 patients, $<1 \%)(\mathrm{p}<0.05)$. During a mean (SD) follow up of 28 (24) months (range $<1$ to 114 months), 90 patients $(20 \%)$ died. Of these, nine $(2 \%)$ died from sudden arrhythmic death; five (1\%) died suddenly, probably as a result of non-arrhythmic causes; 55 $(12 \%)$ died from other cardiac causes (congestive heart failure, myocardial infarction); and 21 (5\%) died from noncardiac causes. The three, five, and seven year survival for arrhythmic mortality was $95 \%$ in patients $\leqslant 50$ years compared with a three year survival of $93 \%$ and a five and seven year survival of $91 \%$ in patients of 51 to 64 years, and a three, five, and seven year survival of $99 \%$ in patients $\geqslant 65$ years. 362 patients $(80 \%)$ received ICD discharges (21 (43) shocks per patient), with a similar incidence among all three patient groups ( $\leqslant 50$ years, $80 \%$; 51 to 64 years, $81 \%$; $\geqslant 65$ years, $79 \%$ ). The time interval between ICD implant and the first ICD treatment was shorter in patients $\geqslant 65$ years $(8$ (8) months) than in patients between 51 and 64 years $(11$ (14) months) or $\leqslant 50$ years (11 (11) months) $(p<0.05)$. Survival time following first appropriate shock was 30 (24) months in patients $\leqslant 50$ years, 30 (26) months in patients of 51 to 64 years, and 19 (20) months in patients $\geqslant 65$ years.

Conclusions-Elderly patients benefit from ICD treatment, and survive for a considerable time after the first treatment. Therefore, elderly patients should be considered candidates for ICD implantation if life threatening ventricular tachyarrhythmias are present.

(Heart 1997;78:364-370)

Keywords: cardioverter-defibrillator; heart failure; sudden death; ICD discharges; elderly patients

Sudden cardiac death is one of the major causes of mortality in western countries, with an incidence of 500000 per year in the United States and 400000 per year in Europe. ${ }^{12}$ Recent controlled clinical trials with antiarrhythmic drugs have raised serious questions about the long term efficacy and benefit of pharmacological treatment for ventricular tachyarrhythmias. ${ }^{34}$ As a result, nonpharmacological alternatives have gained increasing acceptance in the treatment of such patients. ${ }^{56}$ Clinical experience to date suggests that cardioverter-defibrillator (ICD) treatment is an acceptable approach for preventing sudden cardiac death, and more than 50000 patients have received implants worldwide within the last 14 years. ${ }^{6}$ The extent of the clinical benefit of long term survival has been described in many studies; however, it is unknown whether elderly patients will benefit from ICD implantation. ${ }^{78}$ In this study, we compared surgical risk and survival following ICD treatment in three age groups of patients: $\leqslant 50$ years, 51 to 64 years, and $\geqslant 65$ years.

\section{Methods}

PATIENTS

Since January 1984, 450 consecutive patients (394 male, 56 female, mean (SD) age 57 (11) years, range 7 to 78 years) have been included in this retrospective study. At the time of ICD implantation, 81 patients $(18 \%)$ were aged $\leqslant 50$ years, $254(56 \%)$ were between 51 and 64 , and $115(26 \%)$ were $\geqslant 65$ (table 1$)$. The patients in all three groups were functional and without high comorbidity.

\section{PREOPERATIVE TESTING}

Cardiac catheterisation, coronary angiography, and left ventriculography were performed in all patients before implantation. The left ventricular ejection fraction was calculated from the end diastolic and end systolic angiographic frames in a $30^{\circ}$ right anterior oblique projection. Coronary lesions were assessed by visual interpretation and were considered significant when high grade stenosis was present $(\geqslant 75 \%$ of the luminal diameter). Before device
Accepted for publication 10 June 1997 
Table 1 Patient characteristics by age group

\begin{tabular}{|c|c|c|c|}
\hline Demographics & $\begin{array}{l}\text { Group } 1 \\
(\leqslant 50 \text { years })\end{array}$ & $\begin{array}{l}\text { Group } 2 \\
\text { (51-64 years) }\end{array}$ & $\begin{array}{l}\text { Group } 3 \\
(\geqslant 65 \text { years })\end{array}$ \\
\hline No of patients & 81 & 254 & 115 \\
\hline Males $(\%)$ & $64(79 \%)$ & $234(92 \%)$ & $96(83 \%)$ \\
\hline Mean (SD) age (years) & $39(11)$ & $58(4)$ & $70(3)$ \\
\hline Range & $7-50$ & $51-64$ & $65-78$ \\
\hline Mean (SD) follow up (months) & $30(24)$ & $30(26)$ & $19(20)$ \\
\hline Range & $<1-114$ & $<1-112$ & $<1-107$ \\
\hline \multicolumn{4}{|l|}{ Underlying disease } \\
\hline $\mathrm{CAD}$ & $36(44 \%)$ & $188(74 \%)$ & $86(75 \%)$ \\
\hline DCM & $18(22 \%)$ & $42(17 \%)$ & $16(14 \%)$ \\
\hline R/LVD & $5(6 \%)$ & $8(3 \%)$ & $6(5 \%)$ \\
\hline Other & $22(27 \%)$ & $16(6 \%)$ & $7(6 \%)$ \\
\hline ACVB & $7(9 \%)$ & $49(19 \%)$ & $24(21 \%)$ \\
\hline \multicolumn{4}{|l|}{ Vessel disease } \\
\hline 0 & $40(49 \%)$ & $72(28 \%)$ & $31(27 \%)$ \\
\hline 1 vessel & $14(17 \%)$ & $49(19 \%)$ & $27(23 \%)$ \\
\hline 2 vessels & $10(12 \%)$ & $66(26 \%)$ & $29(25 \%)$ \\
\hline 3 vessels & $17(21 \%)$ & $67(26 \%)$ & $28(24 \%)$ \\
\hline \multicolumn{4}{|l|}{ Left ventricular ejection fraction } \\
\hline Mean (SD), \% & $36(16)$ & $32(13)$ & $39(15)$ \\
\hline Range & $12-85$ & $12-85$ & $15-77$ \\
\hline$<40 \%$ & $49(60 \%)$ & $187(74 \%)$ & $61(53 \%)$ \\
\hline$\geqslant 40 \%$ & $32(40 \%)$ & $67(26 \%)$ & $54(47 \%)$ \\
\hline \multicolumn{4}{|l|}{ Arrhythmia history } \\
\hline No arrhythmias & $3(4 \%)$ & $8(3 \%)$ & $4(3 \%)$ \\
\hline SMVT & $16(20 \%)$ & $90(35 \%)$ & $38(33 \%)$ \\
\hline VF & $35(43 \%)$ & $59(23 \%)$ & $32(28 \%)$ \\
\hline $\mathrm{SMVT}+\mathrm{VF}$ & $27(33 \%)$ & $97(38 \%)$ & $40(35 \%)$ \\
\hline \multicolumn{4}{|l|}{ Heart failure } \\
\hline NYHA I & $24(30 \%)$ & $26(10 \%)$ & $6(5 \%)$ \\
\hline NYHA II & $19(23 \%)$ & $109(43 \%)$ & $44(38 \%)$ \\
\hline NYHA II-III & $20(25 \%)$ & $72(28 \%)$ & $34(30 \%)$ \\
\hline NYHA III & $18(22 \%)$ & $47(19 \%)$ & $31(27 \%)$ \\
\hline No of failed antiarrhythmic drugs (SD) & $3(2)$ & $3(2)$ & $3(2)$ \\
\hline Range & $1-8$ & $1-13$ & $1-11$ \\
\hline
\end{tabular}

CAD, coronary artery disease; DCM, dilated cardiomyopathy; R/LVD, right/left ventricular dysplasia; NYHA, New York Heart Association functional class of heart failure; SMVT, sustained monomorphic ventricular tachycardia; $\mathrm{VF}$, ventricular fibrillation.

implantation and after discontinuation of antiarrhythmic drugs for at least five drug half lives, all patients underwent a baseline electrophysiological study. Patients were considered to be candidates for defibrillator implantation on the basis of history and the presence of spontaneous and inducible sustained ventricular tachycardia or fibrillation. ${ }^{5}$

DEVICE IMPLANTATION

After providing written informed consent, all patients were maintained under general anaesthesia throughout the implantation procedure. During the first five years of the study (1984 to 1989), an epicardial defibrillation lead system was used and this was implanted through a median sternotomy or a left anterior thoracotomy. ${ }^{9}$ Using this approach, the leads (two defibrillation patch electrodes, two myocardial screw-in pacing/sensing leads) were attached to the left and right ventricles. In 1990, we began using non-thoracotomy transvenous defibrillation lead systems. The transvenous defibrillation lead electrode system (Endotak lead, CPI, St Paul, Minnesota, USA; TVL lead system, Ventritex, Sunnyvale, California, USA) was advanced through the subclavian or cephalic vein into the right atrium and then to the right ventricle. The distal pacing tip of the lead was lodged in the right ventricular apex and the SVC electrode was positioned anywhere from the right atrium to the innominate vein. After evaluation of the defibrillation threshold, the leads were tunnelled subcutaneously to the abdominal pocket and attached to the pulse generator, which was placed submuscularly.
The implantation procedure was recently reported in detail. ${ }^{9}$

DEFIBRILLATION THRESHOLD TESTING

Before defibrillation threshold testing, the $\mathrm{R}$ wave amplitude from the pacing/sensing leads was measured and a synchronised low energy biphasic shock of 0.1 joule was delivered during sinus rhythm to determine the impedance of the defibrillation leads. For devices with programmable pulse widths, the pulse width was adjusted according to the measured impedance to produce a defibrillation waveform with $65 \%$ first phase tilt. Defibrillation threshold testing was conducted using a programmable stimulation/ cardioverter-defibrillator analyser (model HVS-02, Ventritex, or model ECD, CPI). No patient received antiarrhythmic drugs at the time of implantation. Ventricular fibrillation was induced by rapid ventricular pacing, and initial defibrillation attempts were performed using a 20 joule shock delivered through the HVS-02 external equipment. If ventricular fibrillation was successfully terminated with 20 joules, then additional testing was performed using progressively lower voltages in 5 joule decrements until failure. The voltage was then increased by 5 joule increments until two consecutive, successful conversions occurred; this voltage was defined as the defibrillation threshold. When testing a transvenous defibrillation lead system, if a 20 joule shock did not terminate ventricular fibrillation twice, a subcutaneous patch was implanted over the left fifth intercostal space at the midaxillary line and defibrillation testing was then repeated. After the defibrillation threshold was determined, the pulse generator was connected to the leads, and the ability of the system to detect and terminate induced ventricular fibrillation was again tested with a 20 joule shock.

\section{PREDISCHARGE TESTING}

All patients underwent a predischarge electrophysiological study an average of 7 (2) days after implantation (range four to 13 days); no patient received antiarrhythmic drugs at that time. Before testing, proper lead positioning was confirmed by chest radiography. Ventricular fibrillation was induced by rapid ventricular pacing using non-invasive device features (the period of stimulation was standardised with a duration of 10 to 15 seconds of rapid pacing), proper sensing and termination of the arrhythmia were confirmed, and the defibrillation threshold was reconfirmed. In patients with inducible sustained monomorphic ventricular tachycardia, the safety and efficacy of three different antitachycardia pacing modes were evaluated, as recently described. ${ }^{10}$ In patients whose only clinical rhythm was ventricular fibrillation, one tachyarrhythmia detection zone was programmed, and the first shock defibrillation voltage was set $10 \mathrm{~J}$ higher than the defibrillation threshold. In patients who had induced ventricular tachycardia, the device was programmed with separate detection zones for ventricular tachycardia and ventricular 
fibrillation, and antitachycardia pacing was programmed to the most effective pacing mode. $^{10}$

\section{FOLLOW UP}

Patients were followed in the outpatient clinic every two months. During these visits, the device was interrogated and, depending on the capabilities of the device, the pacing threshold, $\mathrm{R}$ wave amplitude, and lead impedance were measured. When available, stored electrograms were retrieved and analysed. Sudden death was defined as death occurring within one hour after the beginning of symptoms. We classified an sudden arrhythmic death when the postmortem analysis of stored electrograms showed that ventricular tachycardia or ventricular fibrillation was the underlying arrhythmia that was not terminated by the device. In patients with unexpected witnessed deaths we were not able to interrogate the devices postmortem and therefore we classified these as sudden (nonarrhythmic) deaths. All deaths were verified and classified by interviews of relatives and physicians.

STATISTICS

Values are given as mean (SD). Data were evaluated by unpaired Student's $t$ tests, linear trend tests, and Fisher's exact test. A p value of less than 0.05 was considered significant. Life table analysis was performed according to the Kaplan-Meier method (log rank test).

\section{Results}

PATIENTS

Coronary artery disease was present in 310 patients $(69 \%)$, dilated cardiomyopathy in 76 $(17 \%)$, left and/or right ventricular dysplasia in $19(4 \%)$, and other aetiologies (congenital heart disease, valvar heart disease, idiopathic ventricular tachycardia/fibrillation) in the remaining $45(10 \%)$. Symptomatic drug refractory sustained ventricular tachycardia $(\geqslant 30$ seconds) or ventricular fibrillation or both were present in 435 patients (97\%); no patient had life threatening ventricular tachyarrhythmias with an acute myocardial infarction. The remaining 15 patients (3\%) underwent prophylactic ICD implantation according to the MADIT or the CAT study protocols. ${ }^{11}{ }^{12}$ Antiarrhythmic drug treatment had failed to suppress life threatening ventricular tachyarrhythmias in all patients, with a mean of 3.2 (2.9) antiarrhythmic drug trials per patient (range one to 13 drugs per patient) before ICD implantation. The degree of heart failure was assessed by two experienced cardiologists according to the New York Heart Association (NYHA) functional class of heart failure and by angiographically proven left ventricular ejection fraction. In addition to the traditional functional NYHA classification (NYHA I-IV) of heart failure, we added two hybrid categories for patients who could not clearly be classified in one NYHA class by the two interviewers. NYHA class I-II was assigned to patients who had either no signs of heart failure or dyspnoea during severe exercise. NYHA class II-III was assigned to patients with dyspnoea during moderate or mild exercise. Fifty six patients $(12 \%)$ were in NYHA class I-II, $172(38 \%)$ were in NYHA class II, 126 (28\%) were in NYHA class II-III, and the remaining 96 $(21 \%)$ were in NYHA class III. No patients in NYHA class IV were considered candidates for ICD implantation. The mean left ventricular ejection fraction was $35(15) \%$ (range $12 \%$ to $85 \%)$.

PREVIOUS SURGICAL PROCEDURES

One hundred and twenty four patients $(28 \%)$ had had previous surgical procedures: $33(7 \%)$ underwent left ventricular aneurysmectomy with subendocardial resection, $11(2 \%)$ valvar replacement, and $80(18 \%)$ aortocoronary bypass grafting. There were no significant differences in the incidence of aneurysmectomy with subendocardial resection or valve replacement between patients $\leqslant 50$ years of age (three patients, $4 \%$; five patients, $6 \%$ ), or patients between 51 and 64 (six patients, $2 \%$; five patients, $2 \%$ ), whereas patients $\geqslant 65$ years old more often had aneurysmectomy with subendocardial resection (24 patients, 21\%) $(\mathrm{p}<0.05)$. Aortocoronary bypass grafting was performed more often in patients between 51 and 64 years ( 49 patients, $20 \%$ ) or $\geqslant 65$ years (24 patients, $21 \%$ ) than in patients $\leqslant 50$ years $(7$ patients, $9 \%)(\mathrm{p}<0.05)$.

\section{INTRAOPERATIVE RESULTS}

Cardioverter-defibrillator implantation was possible in all patients. From January 1984 to May 1990, epicardial lead systems were implanted in 209 patients (46\%); beginning in May 1990, transvenous lead systems were implanted in 241 patients ( $54 \%$ ) (table 2). The mean $\mathrm{R}$ wave amplitude, measured by the pacing analyser, was 11 (7) $\mathrm{mV}$ (range 3.4 to 33 $\mathrm{mV}$ ); the mean pacing threshold measured by the external device at a $0.5 \mathrm{~ms}$ pulse width was $0.3(0.2) \mathrm{V}$ (range 0.1 to $0.8 \mathrm{~V}$ ); and the mean pacing lead impedance was 434 (97) ohms (range 230 to $600.5 \mathrm{ohms}$ ). Ventricular fibrillation was induced in all patients, and the mean defibrillation threshold was 16 (9) joules (range 2 to 30 joules). No significant differences were found in $\mathrm{R}$ wave amplitude, pacing threshold, pacing lead impedance, or defibrillation threshold among the three patient groups. Transvenous ICD implantation was attempted in 251 patients and was successful in 241 $(96 \%)$. The other 10 patients were successfully implanted with epicardial lead systems. A leads-alone configuration was implanted in 219 patients $(91 \%)$, and an additional subcutaneous patch lead was necessary in 22 (9\%). Cardioverter-defibrillators with monophasic waveforms were implanted in 190 patients (42\%), and 260 (58\%) received biphasic waveform devices. Devices with antitachycardia pacing modes (third generation ICDs) were implanted in 199 patients $(44 \%)$. No significant differences in ICD implantation technique and device technology were observed among the three different patient groups. Additional aortocoronary bypass grafting was performed in 13 patients $(16 \%)$ aged $\leqslant 50$ years, in 40 patients (16\%) with aged between 
Table 2 Intraoperative characteristics by age group

\begin{tabular}{llll}
\hline & $\begin{array}{l}\text { Group } 1 \\
(\leqslant 50 \text { years })\end{array}$ & $\begin{array}{l}\text { Group } 2 \\
(51-64 \text { years })\end{array}$ & $\begin{array}{l}\text { Group } 3 \\
(\geqslant 65 \text { years })\end{array}$ \\
\hline $\begin{array}{l}\text { No of patients } \\
\text { Mean (SD) defibrillation threshold (J) }\end{array}$ & 81 & 254 & 115 \\
$\quad$ VT & $12(10)$ & $13(9)$ & $11(8)$ \\
Range & $2-30$ & $1-30$ & $1-30$ \\
VF & $17(10)$ & $17(11)$ & $15(8)$ \\
Range & $5-30$ & $3-30$ & $2-30$ \\
ICD implant & $36(44 \%)$ & $121(48 \%)$ & $52(45 \%)$ \\
$\quad$ Epicardial & $45(56 \%)$ & $133(52 \%)$ & $63(55 \%)$ \\
$\quad$ Transvenous & $40(89 \%)$ & $121(91 \%)$ & $58(92 \%)$ \\
$\quad \begin{array}{l}\text { Lead-alone } \\
\text { + subcutaneous patch }\end{array}$ & $5(11 \%)$ & $12(9 \%)$ & $5(8 \%)$ \\
Pulse generators & $37(46 \%)$ & $138(54 \%)$ & $52(45 \%)$ \\
$\quad$ Monophasic & $44(54 \%)$ & $116(46 \%)$ & $63(55 \%)$ \\
$\quad \begin{array}{l}\text { Biphasic } \\
\text { Third generation ICD }\end{array}$ & $27(33 \%)$ & $105(41 \%)$ & $67(58 \%)$ \\
\hline
\end{tabular}

ICD, implantable cardioverter-defibrillator; VF, ventricular fibrillation; VT, ventricular tachycardia.

51 and 64 years, and in 12 patients $(10 \%)$ aged $\geqslant 65$ years (NS).

PERIOPERATIVE MORTALITY

Perioperative deaths (within 30 days after ICD implantation) occurred in 13 of 450 patients $(3 \%)$. The cause of perioperative death was congestive heart failure in 10 patients and ventricular arrhythmias in three. Of these, one patient died from recurrent ventricular fibrillation and two from electromechanical dissociation. It is interesting to note that nine of 13 patients who died perioperatively had additional surgical procedures (aortocoronary bypass grafting in eight, mitral valve replacement in one), whereas only four died perioperatively with ICD implantation alone. Perioperative mortality by age group was $4 \%$ (three of 81 patients) in patients $\leqslant 50$ years, $2 \%$ (six of 254 patients) in patients of 51 to 64 years, and 3\% (four of 115 patients) in those $\geqslant 65$ years (NS). Perioperative deaths occurred significantly more often in patients with epicardial lead systems (12 of 209 patients, 5\%) compared with patients having non-thoracotomy transvenous lead systems (one of 241 patients, $<1 \%)(\mathrm{p}<0.05)$.

\section{LONG TERM MORTALITY}

During a mean follow up of 28 (24) months (range $<1$ to 114 months), 90 patients $(20 \%)$ died. Fourteen patients (3\%) died suddenly (within one hour after the beginning of symptoms). Of these, nine $(2 \%)$ died from sudden arrhythmic death and the remaining five $(1 \%)$ died suddenly, probably from nonarrhythmic causes. Fifty five patients (12\%) died from non-sudden cardiac causes (congestive heart failure, myocardial infarction) and 21 (5\%) from non-cardiac causes. The incidence

Table 3 Drug treatment after ICD implantation by age group

\begin{tabular}{|c|c|c|c|}
\hline & Group 1 ( $\leqslant 50$ years) & Group 2 (51-64 years) & Group 3 ( $\geqslant 65$ years) \\
\hline No of patients & 50 & 117 & 92 \\
\hline Digitalis & $8(16 \%)$ & $48(41 \%)$ & $52(57 \%)$ \\
\hline Diuretics & $17(34 \%)$ & $72(62 \%)$ & $66(72 \%)$ \\
\hline$\beta$ Blocker & $1(2 \%)$ & $2(2 \%)$ & $2(1 \%)$ \\
\hline \multicolumn{4}{|c|}{ Antiarrhythmic drugs } \\
\hline Class I & $2(4 \%)$ & $5(4 \%)$ & $11(12 \%)$ \\
\hline Amiodarone & $4(8 \%)$ & $17(15 \%)$ & $12(13 \%)$ \\
\hline Sotalol & $19(38 \%)$ & $50(43 \%)$ & $42(46 \%)$ \\
\hline ACE inhibitors & $18(36 \%)$ & $60(51 \%)$ & $58(63 \%)$ \\
\hline
\end{tabular}

ACE, angiotensin converting enzyme.

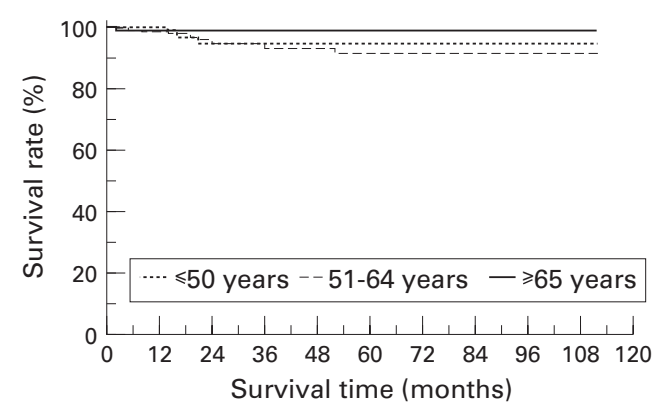

Figure 1 Kaplan-Meier survival curves in implantable cardioverter-defibrillator recipients (incidence of sudden death) in relation to the patient age.

of sudden death was low in all groups (fig 1), and survival from sudden death was similar in all patient groups (91\% to $100 \%)$. However, cardiac and all cause mortality was significantly higher in patients of 51 to 64 years $(34 \%)$ and $\geqslant 65$ years $(19 \%)$ than in patients $\leqslant 50$ years $(45 \%)(\mathrm{p}<0.001)$ (figs 2 and 3). Fourteen patients $(3 \%)$ underwent heart transplantation during follow up: six $(7 \%)$ with an age of $\leqslant 50$ years and eight $(3 \%)$ between 51 and 64 years. No patients underwent heart transplantation in the $\geqslant 65$ age group.

INCIDENCE OF ICD DISCHARGES

During the follow up, 362 patients (80\%) received ICD shocks, with a mean incidence of 21 (43) discharges per patient (range 0 to 233 shocks per patient). The incidence and mean number of ICD discharges were similar among the three patient groups. The interval between ICD implant and the first ICD shock was significantly shorter in patients $\geqslant 65$ years old than in the two younger age groups $(\mathrm{p}<0.05)$ In addition, ICD shocks were observed more often within the first six months after implant in patients $\geqslant 65$ years old than in the two younger age groups (fig 4 ).

\section{ANTITACHYCARDIA PACING TREATMENT}

Reentrant tachycardia can often be terminated by pacing techniques. Although various pacing algorithms have been used and no ideal pacing mode is available at present, antitachycardia pacing is very effective in the majority of arrhythmia episodes. ${ }^{10}$ In the present study, 1732 spontaneous arrhythmic episodes occurred in 159 of 199 patients $(80 \%)$ with third generation ICDs, and all episodes were successfully terminated by the device. One

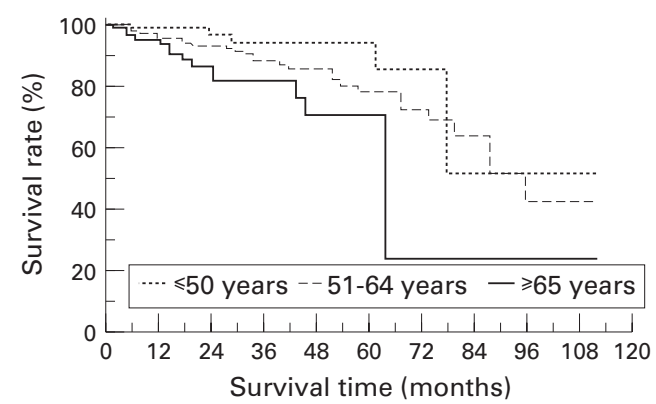

Figure 2 Kaplan-Meier survival curves in implantable cardioverter-defibrillator recipients (incidence of cardiac death) in relation to patient age. 


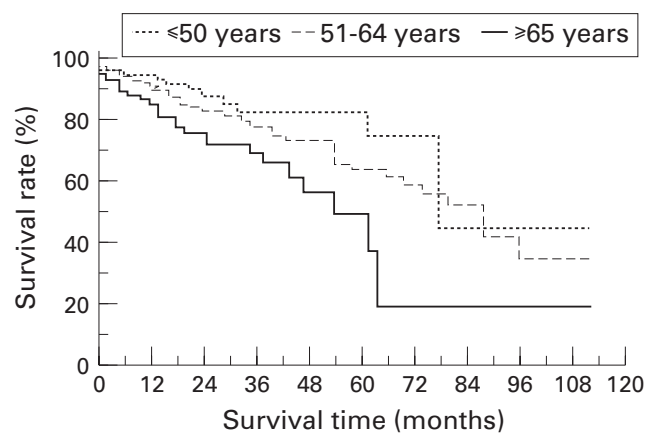

Figure 3 Kaplan-Meier survival curves in implantable cardioverter-defibrillator recipients (total mortality) in relation to patient age.

hundred and eight of these spontaneous episodes were rapid ventricular tachycardia or ventricular fibrillation, resulting in device detection and delivery of defibrillation shock treatment; all episodes were terminated by the device. Antitachycardia pacing was the initial treatment in the remaining 1624 tachycardia episodes (94\%) and was successful in 1542 of them (95\%). Antitachycardia pacing accelerated the rhythm in 49 episodes (3\%), which were terminated by device defibrillation treatment. In the remaining 33 episodes ( $2 \%$ ), pacing treatment was unsuccessful and a device cardioversion treatment terminated the episode. There were no significant differences in antitachycardia termination rates between patients $\leqslant 50$ years old $(94 \%), 51$ to 64 years $(95 \%)$, or $\geqslant 65(95 \%)$.

SURVIVAL AFTER THE FIRST SHOCK

To determine mean survival of all patients in the study and estimate the survival benefit of ICD treatment, we evaluated the time between delivery of the first shock and either the end of the study time period or the patient's death. The mean survival after delivery of the first treatment to the end of follow up was 25 (22) months (range $<1$ to 114 months). By age group, the mean survival time was 30 (24) months (range $<1$ to 114 months) in patients $\leqslant 50$ years, $30(26)$ months (range $<1$ to 112 months) in patients 51 to 64 years, and 19 (20) months (range $<1$ to 107 months) in patients $\geqslant 65$ years. There was no significant difference in mean survival time after the first treatment and the end of follow up among the three patient groups.

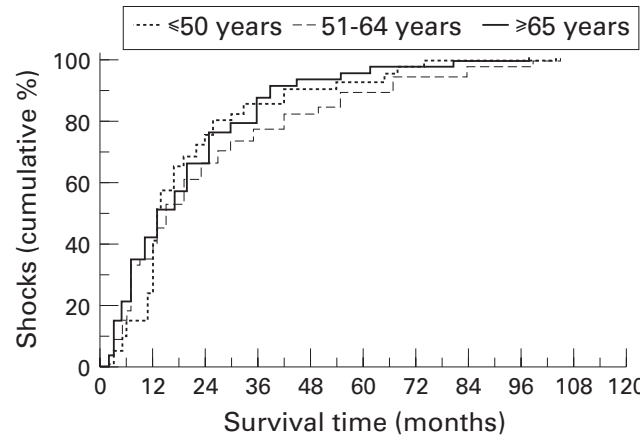

Figure 4 Cumulative occurrence of ICD (implantable cardioverter-defibrillator) shocks after ICD implantation in relation to patient age.
ADDITIONAL PHARMACOLOGICAL TREATMENT During follow up, 108 patients $(24 \%)$ received digitalis, $155(34 \%)$ were treated with diuretics, and five ( $1 \%)$ were given $\beta$ blocking agents (table 3). Class I antiarrhythmic drugs (propafenone, mexiletine, flecainide) were given to 18 patients $(4 \%)$, amiodarone was given to 33 (7\%), and sotalol to $111(25 \%)$. Angiotensin converting enzyme (ACE) inhibitors were prescribed for 136 patients $(30 \%)$. There were significant differences in the incidence of digitalis and diuretic treatment between patients with mild, moderate, or severe heart failure $(\mathrm{p}<0.05)$. Although patients in the two older age groups were prescribed ACE inhibitors more often than patients in the youngest group, these differences were not statistically significant. In addition, no significant differences were observed in antiarrhythmic drug treatment among the different groups.

\section{Discussion}

The treatment of ventricular tachyarrhythmias in the elderly population is a challenging problem. Elderly patients are more predisposed to arrhythmias, less responsive to antiarrhythmic agents, and more susceptible to the adverse effects of these drugs. ${ }^{13} 14$ Results from recent trials have altered the general approach to management of ventricular tachyarrhythmias, and ICDs have gained increasing acceptance as a primary treatment for these disorders. ${ }^{34}$ Though there is little doubt about the efficacy of cardioverterdefibrillator treatment in terminating life threatening ventricular tachyarrhythmias, few studies have compared the outcome after ICD treatment in relation to the patient's age at the time of ICD implantation. ${ }^{781516}$ Hence, whether ICD treatment benefits elderly patients with ventricular tachycardia or ventricular fibrillation has remained a largely unanswered question. ${ }^{17-19}$ In the study reported here we compared the outcome after ICD implantation in three age groups of patients over a time period of more than 11 years.

\section{OPERATIVE RISK}

Studies indicate that perioperative mortality (deaths within 30 days after ICD implantation) has decreased significantly since the advent of non-thoracotomy defibrillation lead systems. ${ }^{20-22}$ These lead systems and other advances, including devices with biphasic waveforms and pectoral implantation techniques, have reduced overall perioperative mortality to less than $1 \%^{23-25}$ and have enabled cardioverter-defibrillators to be implanted in the catheterisation laboratory. ${ }^{26}{ }^{27}$ This decrease in operative risk has occurred while the mean patient age has remained constant. In the present study, perioperative deaths occurred in 13 patients (3\%), with no significant differences among the three patient groups. These data are in accordance with results reported by Tresch et $a l^{16}$ with perioperative deaths of three to four per cent in younger or older patients; however, our data contrast with results reported by Kleman et al, ${ }^{7}$ who studied 38 patients $\geqslant 75$ years and found an operative 
mortality of $5.3 \%$ compared with a control group of patients aged 59 (11) years who had an operative mortality of $1.3 \%(p=0.22)$. In the present study, the most significant predictor of perioperative death appeared to be the type of lead system implanted: less than $1 \%$ of patients receiving non-thoracotomy lead systems died within 30 days of device implantation, compared with $5 \%$ of patients receiving epicardial systems.

RISK OF SUDDEN DEATH

Previous studies with different defibrillation systems and surgical implant techniques have shown that cardioverter-defibrillator treatment can reduce sudden cardiac death in patients with life threatening ventricular tachyarrhythmias to an annual incidence of less than $1 \%{ }^{28-30}$ Even in patients with left ventricular dysfunction, the risk of sudden death is low and five year survival rates of $96 \%$ to $99 \%$ have been reported for arrhythmic mortality. ${ }^{6}{ }^{17} 1931$ In the present study we found three, five, seven, and nine year survival rates from sudden death of $91 \%$ to $99 \%$ for arrhythmic mortality in all patients, independent of age. These data agree with observations by Kleman et $a l^{7}{ }^{7}$ who reported no sudden cardiac death in elderly patients, but two cases of arrhythmic death in the younger cohort.

SURVIVAL AFTER ICD IMPLANTATION

Although prevention of sudden cardiac death is a major goal in clinical cardiology, appropriate and aggressive treatment of impaired left ventricular function to prevent death from heart failure is necessary in ICD patients. ${ }^{32} 33$ Our data show an excellent rate of survival from sudden death, independent of the patient's age, but an increased incidence of heart failure deaths in patients $\leqslant 51$ years old. In addition, total mortality was clearly influenced by patient age, and the worst outcome was observed in patients of $\geqslant 65$ years. Two year actuarial survival was $87 \%$ in patients $\leqslant 50$ years, $83 \%$ in those of 51 to 64 years, and $76 \%$ in those $\geqslant 65$ years (NS). These survival rates are in agreement with data from Kleman et al, who observed a two year actuarial survival of $76 \%$ in patients $\geqslant 75$ years old and $81 \%$ in patients with a mean age of 59 years ( $\mathrm{p}=$ $0.53) .^{7}$ Tresch et $a l^{16}$ calculated survival curves and showed similar survival rates in younger and elderly patients, with approximately $90 \%$, $87 \%$, and $80 \%$ of the patients alive at one, two, and three years, respectively. It should be noted that there were some differences in drug treatment between the younger and the older patients. It has been shown that treatment of heart failure with digitalis, diuretics, or ACE inhibitors is a major factor in prolonging life in patients with left ventricular dysfunction. ${ }^{7} 81923$

\section{INCIDENCE OF TREATMENT}

The incidence of appropriate cardioverterdefibrillator treatment over a two to five year follow up period has been reported to be in the range of $33 \%$ to $70 \% .^{34}{ }^{35}$ In the present study, the incidence of appropriate ICD treatments was high, occurring at a rate of $79 \%$ to $81 \%$ independent of the patients' age. In addition, the time interval between ICD implantation and the delivery of the first treatment was relatively short, with a mean interval of eight to 11 months. About $50 \%$ of patients in each group had ICD discharges within the first six months after ICD implantation. However, the interval between implantation and first ICD treatment was significantly shorter in patients $\geqslant 65$ years old. These data suggest that patient's age may play some role in the delivery of cardioverterdefibrillator treatment, but all age groups used device treatment at similar rates.

PROBLEMS AND COMPLICATIONS

It has been reported that elderly patients are more susceptible to the adverse effects of antiarrhythmic drugs. ${ }^{36}{ }^{37}$ For this reason, many clinicians recommend the use of implantable cardioverter-defibrillators in elderly patients with life threatening ventricular tachyarrhythmias. ${ }^{783637}$ However, despite the excellent record of ICD treatment in preventing sudden deaths, its problems and complications are well known. ${ }^{38-41}$ Theoretically, it seems likely that cardioverter-defibrillator treatment may be associated with an increased risk of morbidity and mortality in elderly patients and therefore the benefits of preventing sudden death and prolonging life may be somewhat attenuated in this age group. However, this was not observed in the present study.

CLINICAL IMPLICATIONS

Cardioverter-defibrillator treatment is feasible in patients with life threatening ventricular tachyarrhythmias and in a selected population of elderly patients at high risk of sudden cardiac death. In this study, ICDs were not associated with increased perioperative mortality in the oldest patient population. Protection from sudden arrhythmic death and overall long term survival were similar to those in a younger cohort of ICD patients. Implantable cardioverter-defibrillators may benefit all patients and prolong life. Therefore, patients with ventricular tachycardia/fibrillation should be considered as candidates for ICD treatment, independent of age.

\section{STUDY LIMITATIONS}

This was a non-randomised study. Although it would have been preferable to compare age related survival rates among two demographically similar groups, given either conventional drug treatment or ICD treatment, we feel that ethical considerations preclude such a study. An additional limitation was the uncontrolled treatment of patients with a variety of antiarrhythmic and cardioactive drugs during the follow up period. The role of antitachycardia pacing is difficult to analyse in the present patient population because at the start the third generation ICDs were not available; therefore we excluded antitachycardia pacing treatments from our analysis. In addition, while it is possible to differentiate appropriate from inappropriate shocks with the present generation of ICDs, this was not possible in first and second generation devices. 
1 Cappucci A, Boriani G. Drugs, surgery, cardioverter defibrillator: a decision based on the clinical problem. Pacdefibrillator: a decision based on the cl.

2 Gillum RF. Sudden coronary death in the United States. Circulation 1989;79:756-65.

3 The Cardiac Arrhythmia Suppression Trial (CAST) Investigators. Preliminary report: effect of encainide and flecainide on mortality in a randomized trial of arrhythmia suppression after myocardial infarction. $N$ Engl $\mathcal{F ~ M e d ~}$ 1989;321:406-12.

4 The Cardiac Arrhythmia Suppression Trial II Investigators. Effect of the antiarrhythmic agent moricizine on survival
after myocardial infarction. $N$ Engl $\mathcal{F}$ Med 1992;327:22733.

5 Trappe HJ, Pfitzner P, Fieguth HG, Wenzlaff P, Kielblock B, Klein H. Nonpharmacological therapy of ventricular tachyarrhythmias: observations in 554 patients. Pacing Clin tachyarrhythmias: observation
Electrophysiol 1994;17:2172-7.

6 Nisam S, Kaye SA, Mower MM, Hull M. AICD ${ }^{\mathrm{TM}}$ automatic cardioverter-defibrillator clinical update: 14 automatic cardioverter-defibrillator clinical update: 14 Electrophysiol 1995; 18:142-7.

7 Kleman JM, Pinski SL, Morant VA, Wilkoff BL, Castle LW. ICDs in the very elderly: short- and long-term outcome [abstract]. Pacing Clin Electrophysiol 1994;17:835.

8 Lehmann MH, Roberts D, Church TR, PCD Investigators. Potential survival benefit from investigational devices in patients 65 yrs: lessons from the implantable cardioverter defibrillator (ICD) experience [abstract]. $7 \mathrm{Am}$ Coll Cardio 1995;23:22A

9 Trappe HJ, Klein H. Clinical results with implantable cardioverter-defibrillator therapy. In: Singer I, ed. Implantable cardioverter-defibrillator. Mount Kisco, New York: Futura Publishing Company, 1994:487-505.

10 Trappe HJ, Klein H, Kielblock B. Role of antitachycardia pacing in patients with third generation cardioverter defibrillators. Pacing Clin Electrophysiol 1994;17:506-13.

11 Moss AJ. Prospective antiarrhythmic studies assessing prophylactic pharmacological and device therapy in high prophylactic pharmacological and device therapy in high 694-6.

12 The Cardiomyopathy Trial Investigators. Cardiomyopathy trial. Pacing Clin Electrophysiol 1993;16:576-81.

13 Aronow WS. The management of ventricular arrhythmias in older patients after CAST. Drugs Aging 1995;2:112-24.

14 Benjamin EJ, Anderson KM, Plehn JF, Comai K, Fuller D, Evans JC, et al. The impact of age on left ventricular diastolic function in healthy subjects from the Framingham Heart Study [abstract]. F Am Coll Cardiol 1991;17:329A.

15 Thakur RK, Tresch DT, Troup PJ, Chapman PD, Wetherbee JN. Are automatic internal cardiac defibrillators justified in the elderly? [abstract] Clin Res 1988;36:830A.

16 Tresch DD, Troup PJ, Thakur RK, Wetherbee JN. Benefits of cardioverter/defibrillator implantation for elderly patients. Cardiol Board Rev 1992;9:63-70.

17 Schlepper M, Neuzner J, Pitschner HF. Implantable cardioverter defibrillator: effect on survival. Pacing Clin Electrophysiol 1995;18:569-78.

18 Akhtar M, Jazayeri M, Sra J, Tschou P, Rovang K, Blanck Z, et al. Implantable cardioverter defibrillator for prevention et al. Implantable cardioverter defibrillator for prevention of sudden cardiac death in patients with ventricular tachycardia and ventricular fib

19 Böcker D, Block M, Isbruch F, Wiethold D, Hammel D Borggrefe $\mathrm{M}$, et al. Do patients with an implantable defibrillator live longer? f Am Coll Cardiol 1993;21:163844.

20 Bardy GH, Hofer B, Johnson G, Kudenchuck PJ, Poole JE, Dolack GL, et al. Implantable transvenous cardioverterdefibrillators. Circulation 1993;87:1152-68.

21 Trappe HJ, Klein H, Fieguth HG, Kielblock B, Wenzlaff P, Lichtlen PR. Initial experience with a new transvenous defibrillation lead system. Pacing Clin Electrophysiol 1993; 16:134-40.

22 Kelly PA, Mann DE, Harken AH, Manart FD, Reiter MJ. Implantation of an automatic defibrillator using a new nonthoracotomy approach. Pacing Clin Electrophysiol 1994; $17 \cdot 2247-54$

23 Trappe HJ, Wenzlaff P, Klein H, Pfitzner P, Fieguth HG, Kielblock B, et al. Results and experiences of cardioverterdefibrillator therapy after 10 years: observations in 353 patients. $Z$ Kardiol 1995;84:222-31

24 Trappe HJ, Fieguth HG, Pfitzner P, Heintze J, Wenzlaff P, Kielblock B. Epicardial and nonthoracotomy defibrillation ead systems combined with a cardioverter defibrillator. Pacing Clin Electrophysiol 1995;18:127-32.

25 Raviele A, Gasparini G, for the Italian Endotak Investigator Group: Italian multicenter clinical experience with endocardial defibrillation: acute and long-term results in 307 patients. Pacing Clin Electrophysiol 1995;18:599-608.

26 Trappe HJ, Pfitzner P, Heintze J, Kielblock B, Wenzlaff P, Fieguth HG, et al. Cardioverter-defibrillator implantation in the catheterization laboratory: initial experiences in 48 patients. Am Heart f 1995;129:259-64.

27 Fitzpatrick AP, Lesh MD, Epstein LM, Lee RJ, Siu A, Merrick S, et al. Electrophysiological laboratory, electrophysiologist-implanted, nonthoracotomy-implantable cardioverter/defibrillators. Circulation 1994;89:2503-8.

28 Sweeney MO, Ruskin JN. Mortality benefits and the implantable cardioverter-defibrillator. Circulation 1994;89: $1851-8$

29 Brooks R, Garan H, Torchiana D, Vlahakes GJ, Dziuban S, Newell J, et al. Three-year outcome of a nonthoracotomy approach to cardioverter-defibrillator implantation in 189 consecutive patients. Am f Cardiol 1994;74:1011-5.

30 Zipes DP, Roberts D. Results of the international study of the implantable pacemaker cardioverter-defibrillator. A comparison of epicardial and endocardial lead systems. The Pacemaker-Cardioverter-Defibrillator Investigators. Circulation 1995;92:59-65.

31 Axtell K, Tchou PJ, Akhtar M. Survival in patients with depressed left ventricular function treated with implantable defibrillator. Pacing Clin Electrophysiol 1991;14:291-6.

32 Trappe HJ, Fieguth HG, Klein H, Wenzlaff P, WeberConrad O, Schöhl W, et al. Role of the underlying etiology in patients with an implantable cardioverter defibrillator. Med Klin 1993;88:362-70.

33 Trappe HJ, Wenzlaff P, Pfitzner P, Fieguth HG. Long-term follow-up of implantable cardioverter defibrillator patients with mild, moderate, or severe impairment of left ventricular function. Heart (in press)

34 Myerburg RJ, Luceri RM, Thurer R, Cooper DK, Zaman L, Interian A, et al. Time to first shock and clinical outcome in patients receiving an automatic implantable cardioverterdefibrillator. F Am Coll Cardiol 1989;14:508-14.

35 Vester EG, Kuhls S, Altenvoerde G, Strauer BE. Ten-years follow-up after automatic cardioverter/defibrillator implantation: determining factors of survival and shock incidence [abstract]. Eur $\mathcal{F}$ Cardiol 1994;15:187.

36 Aronow WS. The management of ventricular arrhythmias in older patients after CAST. Drugs Aging 1995;6:112-24.

$37 \mathrm{Kim}$ CH, Daubert JP, Akiyama T. Antiarrhythmic agents in older patients. Current state of knowledge. Drugs Aging 1994;4:462-9.

38 Kelly PA, Cannom DS, Garan H, Mirabal GS, Harthorne JW, Hurvitz RJ, et al. The automatic implantable cardioverter defibrillator: efficacy, complications and survival in patients with malignant ventricular arrhythmias. $\mathcal{f}$ Am Coll Cardiol 1988:11:1278-86.

39 Grimm W, Flores BT, Marchlinski FE. Complications of implantable cardioverter defibrillator therapy: follow-up of 241 patients. Pacing Clin Electrophysiol 1993;16:218-22

40 Trappe HJ, Pfitzner P, Fieguth HG, Klein H. Infections after cardioverter defibrillator implantation: observations in 335 patients during a ten-year period. Br Heart f 1994;73:20-4.

41 Tresch DD, Platia EV, Guarnieri T, Reid PR, Griffith LSC. Refractory symptomatic ventricular tachycardia and ventricular fibrillation in elderly patients. Am f Med 1987;83: 399-404. 